\title{
Imagens/memórias da Biblioteca Pública de Santa Catarina: uma leitura da memória volátil fixada pela fotografia (1980 - 2011)
}

Gisela Eggert-Steindel

Doutora em Educação e Mestre em Ciência da Informação. Professora do Departamento de Biblioteconomia e Gestão da Informação no Centro de Ciências Humanas e da Educação (FAED/UDESC)

José Augusto da Silva Neto

Graduado em Biblioteconomia, com habilitação em Gestão da Informação. Bolsista PROBIC/UDESC

Ana Caroline Remor Corrêa

Graduada em Biblioteconomia, com habilitação em Gestão da Informação. Bolsista PROBIC/UDESC.

Ana Clara Mitsuko Wada

Graduanda em Biblioteconomia, com habilitação em Gestão da Informação.Bolsista/ I.C. voluntária/UDESC

Luciane Gonçalves Toledo

Graduada em Biblioteconomia, com habilitação em Gestão da Informação (UDESC) Graduanda em Jornalismo/UFSC

O objeto de investigação foi um conjunto de mais de quatro mil fotografias da Biblioteca Pública do Estado de Santa Catarina (BPSC), produzidas pela instituição ou por instituições parceiras, como a Universidade do Estado de Santa Catarina. Pretendeu-se apreender as representações eivadas ao longo do tempo sobre a biblioteca, através da fotografia. Trata-se de um estudo descritivo quanti-qualitativo, que adotou princípios dos estudos culturais e procedimentos a partir do campo da Antropologia, a fotoetnografia. Esse material visual também dialogou com os dados analisados nos relatórios administrativos compreendidos no período de 1980 a 
2011 da biblioteca. O estudo revela intensa ação cultural; descortina uma instituição preocupada com a formação continuada, quer de seus funcionários, quer de interessados da comunidade local; estampa um edifício conhecimento em meio aos estabelecimentos financeiros e comerciais da capital catarinense; aponta uma representação dos fazeres da biblioteca (as práticas bibliotecárias que dão andamento ao cotidiano da biblioteca); revela formas das ações de limpeza e manutenção desse edifício; e o mobiliário e os equipamentos estampados pela fotografia mostram as diferentes fases tecnológicas da biblioteca. As imagens estampam, enquanto noção de representação, uma instituição pública de leitura que se movimenta em favor do público infantil, um lugar de formação e lazer para o adulto, um espaço sempre disponível à espera de seus consulentes, leitores ou utilizadores e representa uma memória para (RE)CONHECER a Biblioteca Pública de Santa Catarina.

Palavras-chave: Biblioteca Pública de Santa Catarina (BPSC) - Imagens (1980-2011); Biblioteca Pública de Santa Catarina (BPSC) - Memórias; Representações culturais; Ação cultural; Formação continuada.

\section{Images/memories of the Public Library of Santa Catarina: a reading of volatile memory photography by fixed (1980 - 2011)}

The object of investigation was a set of more than four thousand photographs of the Public Library of the State of Santa Catarina (BPSC), produced by the institution or partner institutions such as the University of the State of Santa Catarina. It was intended to seize the representations tainted over time about the library through photography. This is a descriptive quantitative and qualitative, which adopted principles of cultural studies and procedures from the field of Antropolgia the fotoetnografia. This visual material also spoke with the data analyzed in administrative reports included in the period 1980 to 2011 the library. The study reveals intense cultural action; reveals an institution concerned with continuing education, or its employees or stakeholders of 
the local community; stamp a building knowledge among the financial institutions and the commercial capital of Santa Catarina; shows a representation of the doings of the library (library practices that give the daily progress of the library), reveals ways of cleaning and maintenance actions that building, furniture and equipment for the printed photograph shows the different stages of technological library. The images adorn the notion of representation as an institution pubic reading that moves in favor of the child audience, a place of leisure and training for adults, a space always available waiting for their consultants, readers or users and represents a memory for (RE) KNOW the Public Library of Santa Catarina.

Keywords: Public Library of Santa Catarina (BPSC) Images (1980-2011); Public Library of Santa Catarina (BPSC) - Memories; Cultural representations; Cultural action; Continuing education.

\section{Considerações iniciais}

Pautado na pergunta - Quais as possíveis representações estampadas no conjunto de fotografias da e sobre a Biblioteca Pública de Santa Catarina?- uma instituição pública de leitura, o presente trabalho quer expressar os resultados alcançados no projeto de pesquisa intitulado "Imagens da e sobre a Biblioteca Pública de Santa Catarina: uma leitura da memória volátil fixada pela fotografia (1980 - 2011)".

O objetivo geral da investigação foi (re)conhecer uma memória e suas possíveis representações nos itens fotográficos da e sobre a Biblioteca Publica de Santa Catarina, ao longo de um período de sua existência como instituição de leitura, que preserva a memória intelectocultural de Santa Catarina, operacionalizada nos seguintes objetivos específicos: inventariar o conjunto fotográfico existente nos arquivos, nas diferentes Divisões da Biblioteca ou aquelas produzidas na biblioteca, durante o programa de extensão Biblioteca Pública de Santa Catarina: um modelo de Gestão, convênio Universidade do Estado de Santa Catarina (UDESC)/Fundação Catarinense de Cultura (FCC); apreender uma memória "representada" nos itens fotográficos; construir um modelo para descrição e futura migração do conjunto fotográfico do suporte impresso para o meio digital, assegurando a preservação dos itens fotográficos e estruturar em software o conjunto fotográfico digital, capturado em diferentes momentos do projeto de extensão (UNIVERSIDADE DO ESTADO DE SANTA CATARINA, 2010).

O arcabouço teórico-metodológico adotado calcou-se em estudos culturais que tomam a noção de representação como uma categoria de interpretação. A noção de representação é entendida como a 
presentificação de uma ausência. Em outras palavras, "[...] As representações são a presentificações de uma ausência, em que representante e representado guardam entre si relações de aproximação e distanciamento" (PESAVENTO, 2008, p. 14). Nessa clave, o conjunto de itens fotográficos pode fazer presente o ausente. Do ausente, aqui representado nos itens fotográficos, pode-se inferir que este é o modo material de criar a memória do realizado na instituição. A representação, isenta de julgamentos, compõe-se de imaginário "[...] sobre o mundo do vivido, do visível e do experimentado [...] se apóia sobre os sonhos, desejos e medos de cada época, isto é, sobre o não-tangível nem visível, que passa, porém, a existir e a ter força de real aquele o vivenciam" (PESANVENTO, 2008, p. 14).

Do campo da Antropologia, utilizou-se o aporte teórico da fotoetnografia, pela possibilidade de organização e leitura dos itens fotográficos (ACHUTTI, 2004). Segundo Barros et al. (1998), a Antropologia tinha como tradição disciplinar a observação, a participação e a descrição; contudo, ao final do século XX, incorporou a fotografia aos estudos antropológicos nas pesquisas de campo, na análise dos dados e na construção dos textos. Nesse sentido, aqui se aposta em uma forma de aproximar os recursos da fotografia ao campo da Biblioteconomia, como o fez o campo da História.

Achutti (2004) afirma que a utilização da fotografia na Antropologia, potencializa o estudo do dinamismo das populações dos grandes centros urbanos, a partir de um questionamento de seu "savoir-faire". O uso desse recurso nos estudos modernos revelou uma disciplina descritiva mais aprofundada e, nesse sentido, Barros et al. (1998) argumentam que a fotografia ajudou na interação do pesquisador com o grupo estudado.

O diálogo científico com a fotografia facilitou o trabalho do etnógrafo no que se refere à interpretação dos dados, podendo auxiliar o pesquisador a chegar a novas conclusões, após o trabalho em campo. Para esse autor, o uso da fotografia no campo da Antropologia resulta em uma Antropologia crítica, isto é, a fotografia não é um "espelho da realidade", pois esta, no ato de fotografar, se orienta por critérios próprios (intencionalidades), como escolha da imagem e dos equipamentos mais apropriados à construção de uma imagem. Em outras palavras, no momento da captura da imagem, o observador pode revelar ou esconder elementos. Nessa direção, Achutti (2004, p. 111) nos ensina:

[...] as fotografias são recortes arbitrários, traduções da realidade. Suas margens delimitam as escolhas feitas pelo fotografo para demarcar o tempo e o espaço; elas são o resultado de um só gesto, um gesto último e definitivo, aquele de apertar o disparador; é um ato intencional determinado pelo ponto de vista particular daquele que olha $[\ldots]$. 
Debruçar-se sobre esse conjunto de itens fotográficos entre as muitas questões que se puderam levantar permite afirmar que as informações fotográficas são possibilidades da guarda de uma memóriadocumento, não apenas do tempo do passado, mas uma memória para o tempo futuro.

A fotografia, desde seu nascimento no século XIX até os dias de hoje, já enfrentou diferentes adversidades, quer de preconceitos relacionados a suas técnicas mecânicas, quer de imprecisão de seu caráter documental. No entanto, difundiu-se pela sociedade desde o estúdio fotográfico até o uso das máquinas portáteis e instantâneas, tornando fotógrafo o homem comum, prolongando indefinidamente no papel fotográfico o cotidiano social de pessoas, instituições e famílias modernas. $\mathrm{Na}$ interpretação de Koury (1998), a fotografia, quando pensada como representação do passado, mesmo que instantaneamente, possibilita uma estampa da condição social do indivíduo, da sua institucionalização, de sua existência no mundo em geral.

$\mathrm{Na}$ atualidade, existem recursos, como a digitalização da fotografia, que permitem corrigir o processo de registro. Segundo Vestal (1998), é importante lembrar que por trás de cada foto existem contextos e sentimentos impossíveis de alterar. O autor afirma que a digitalização e a manipulação do produto fotográfico são polêmicas, visto a facilidade de adulteração, o que nos remete às questões sobre a veracidade das fotografias atuais.

Assume-se, no presente trabalho, que a fotografia digital ampliou as possibilidades de captura dos momentos e movimentos da biblioteca aqui estudada, mesmo no erro ou imperfeição do "click" de quem fotografou as diferentes atividades na biblioteca, utilizando esse recurso tecnológico.

\subsection{Procedimentos adotados}

Esclarece-se que os itens desta pesquisa foram de aproximadamente 900 fotografias impressas e cerca de 80 digitais, essas sob a custódia da BPSC (no período de 1980 a 2008). Somam-se a esse conjunto, 3.479 fotografias digitais essas sob a responsabilidade do Departamento de Biblioteconomia e Gestão da Informação (DBI/UDESC). Este último número de fotografias digitais e seu modo particular de expressão resultaram do programa de extensão Biblioteca Pública de Santa Catarina: um modelo de gestão em parceria, firmada entre a Universidade do Estado de Santa Catarina (UDESC) e a Fundação Catarinense de Cultura (FCC), em 2008. Destaca-se que esse programa de extensão objetivou prestar assessoria gerencial e técnica à BPSC, solicitação originada em fins de 2008 da FCC à Pró-Reitoria de Extensão, Cultura e Comunidade (UDESC) (UNIVERSIDADE DO ESTADO DE SANTA CATARINA, 2010, p. 6).

Do estudo, resultou um inventário do material fotográfico impresso, com o intuito do registro e preservação dos itens impressos. O inventário permitiu, ainda, propor, com base em pesquisa exploratória realizada por 
Santos (2010), um modelo de ficha de indexação, com vistas à digitalização dos itens fotográficos.

No tocante à digitalização, vale ressaltar o argumento de Vestal (1998) citado anteriormente e lembrar que há estudiosos que mantêm o método tradicional de captura e manipulação das fotografias, tendo em mente que imperfeições existem naturalmente no mundo. Por que, então, não mantê-las nas fotografias?

Nesse trabalho referente ao acervo digital, o mesmo foi organizado pelo modo hierárquico de descritores no software Picasa, de forma que fosse possível uma leitura dos itens fotografados, mantê-los sob guarda, com possibilidade de consulta por parte de estudiosos e interessados. Este último material deverá integrar o acervo fotográfico da Biblioteca Pública de Santa Catarina.

Ressalta-se que o material visual dialogou, de algum modo, com os dados analisados nos relatórios administrativos relativos ao período de 1980 a 2010 da biblioteca, analisados em pesquisa anterior, sob o título: "A Biblioteca Pública de Santa Catarina: entre documentos e falas, um lugar de práticas culturais".

Ditas essas primeiras palavras, o conjunto dessas imagens constituem, de certo modo, um documento-memória do fazer dos funcionários e indícios paradigmáticos da própria instituição.

\section{Imagens do impresso ao digital}

\subsection{Nascidas da luz para um enquadramento sobre o papel (1980 a 2008)}

A literatura universal e depoimentos de personalidades reconhecidas de diversas áreas em diferentes momentos se reportam à biblioteca pública como lugar de experiência com a leitura e o saber. Toda biblioteca, embora com mais ênfase uma biblioteca pública, congrega diferentes vozes, diferentes utilizadores e/ou consulentes, leitores, polifonias diversas e, por que não, afirmar diferentes alquimias entre 0 oral e o escrito. No presente texto, objetiva-se interpretar não o leitor, o autor/escritor, figuras coladas a esse tipo de instituição cultural, mas lançar luzes sobre as práticas e movimentos dessa biblioteca, capturados através do feixe de luz - a fotografia - no período compreendido entre 1980 e 2008 e, assim, tratar das representações da e sobre a Biblioteca Pública de Santa Catarina nesse período.

O inventário do conjunto fotográfico impresso revelou que a fotografia em cor é mais recorrente, porém a qualidade de imagem preservada vem sofrendo com a ação do tempo, isto é, com a incidência da luz, da umidade e de outros fatores que fragilizam o suporte fotográfico. No quadro abaixo, mostram-se alguns dos aspectos identificáveis nessas fotografias impressas.

Quadro 1 - Caracterização do conjunto fotográfico impresso colorido 
Imagens/memórias da Biblioteca Pública de Santa Catarina: uma leitura da memória volátil fixada pela fotografia (1980 2011)
Gisela Eggert-Steindel; José Augusto da Silva Neto; Ana Caroline Remor Corre Marques; Ana Clara Wada Mitsuko Wada; Luciane Gonçalves

\begin{tabular}{lc}
\hline Fotos identificadas por ano e evento & 655 \\
Fotos sem identificação de datas & 136 \\
Fotos sem identificação de eventos & 32 \\
Fotos sem qualquer identificação & 66 \\
Subtotal 1 & $\mathbf{8 8 9}$ \\
\hline
\end{tabular}

Fonte: Dados da pesquisa

Nessa mesma linha de raciocínio, no entanto, no que diz respeito ao conjunto de fotografias em preto e branco $(P \times B)$, o quantitativo de 83 fotos é bastante insignificante, apontando uma mudança de recursos tecnológicos adotados por aqueles que, sob uma designação expressa ou vontade deliberada, capturavam momentos e movimentos da biblioteca, a fim de preservar imagens desse tempo/evento. Ver o Quadro 2.

Quadro 2 - Caracterização do conjunto fotográfico impresso (PXB)

$\begin{array}{ll}\text { Fotos identificadas por data e evento } & 52 \\ \text { Fotos sem identificação de evento } & 01 \\ \text { Fotos sem identificação } & 30 \\ \text { Subtotal 2 } & \mathbf{8 3}\end{array}$

Fonte: Dados da pesquisa.

Já no Quadro 3, observa-se uma tímida presença do "click" digital na captura de imagens até próximo aos anos 2008, agora já do século XXI. O caminho, certamente, estava aberto à utilização dessa tecnologia na BPSC.

Quadro 3 - Caracterização do Conjunto Fotográfico Digital

\begin{tabular}{ll} 
Fotos identificadas por data e evento & 35 \\
Fotos sem identificação & 45 \\
Subtotal 3 & $\mathbf{8 0}$ \\
& \\
TOTAL $\mathbf{1 + 2 + 3}$ & $\mathbf{1 . 0 5 2}$ \\
\hline
\end{tabular}

Fonte: Dados da pesquisa.

Dessa leitura mais pragmática, é necessário destacar que esse conjunto de registros fotográficos impressos (em cor ou em preto e branco) e digital, do período 1980 a 2008, sob tutela da BPSC, que totalizam 1.052 fotos, 991 têm alguma identificação o que serve como pista para a indexação e registro de uma história e uma memória da biblioteca; já cerca 141 fotografias não têm qualquer informação que possa auxiliar na identificação de acontecimentos e/ou eventos da biblioteca nesse período. Nesse momento, deve-se recorrer à história oral, junto aos funcionários, para levantar importantes dados não existentes nas fotografias. 


\subsubsection{Outras Leituras: ainda dos anos $80 / 90$ do Século $\mathbf{X X}$}

A população brasileira, que nesse período vivencia os primeiros esforços da democratização do País, enfrenta a instalação de diferentes planos econômicos e as primeiras eleições diretas nas esferas da Federação. Há uma recorrência na captura de imagens que retratam diferentes comemorações anuais entre 1984 e 1994, com destaque para as comemorações do $138^{\circ}$ e do $139^{\circ}$ aniversário da biblioteca no mês de maio de cada ano, respectivamente com 115 e 44 fotografias. Mesmo sem dar importância ao quantitativo, é correto afirmar a diversidade das imagens capturadas nesse período, em relação as que retratam as atividades desenvolvidas nos setores da biblioteca inerentes à guarda da memória intelectual do estado, a dinamização de ações culturais e imagens fotográficas, revelando as mudanças de layout da biblioteca ao longo do tempo e o incremento de tecnologias de informação e comunicação iniciadas principalmente em fins dos 90 do século XX.

\subsection{Nascidas da luz para o infinito: o frágil digital}

O conjunto fotográfico identificado no formato digital representa uma explosão de imagens. Nos primeiros sete anos do século XXI até aproximadamente 2007, foram identificadas aproximadamente 80 fotos digitais, como apontado anteriormente. A mudança será impactante nos anos seguinte. Uma das variáveis desse impacto provavelmente foi o barateamento do acesso à tecnologia digital fotográfica e, pode-se arriscar dizer, em razão da melhoria do nível econômico do País.

Assim, de uma tímida quantidade de fotos digitais que retratam imagens, como a semana do servidor, a reabertura do espaço cultural, as comemorações dos 149 anos da instituição, eventos realizados no auditório, visitas guiadas, apresentações teatrais e imagens externas da biblioteca, sucede um quantitativo digital crescente de modo geométrico, que resultou em 3.479 fotografias digitais. Esse último montante decorreu de atividades de pesquisa e extensão, desenvolvidas por professores do Departamento de Biblioteconomia e Gestão da Informação, entre os anos de 2009 e 2011, material de leitura, como segue.

\subsubsection{Leituras e palavras das muitas imagens congeladas pelo ato fotográfico}

A fotografia, no entendimento de Kossoy (2009), representa, em seu conteúdo, uma interrupção do tempo, assim como da vida. Para ele, o fragmento selecionado do real permanecerá interrompido, registrado e, de certo modo, isolado na bi dimensão da superfície do sensível. Como o livro, para assumir seus sentidos, depende do leitor, a fotografia também tomará sentido só e somente com a leitura do leitor de imagens. 
Da mesma maneira, a fotografia do conjunto em questão assume um sentido próprio para os que participaram de sua produção ou nela estão estampados. Não se limitará a isso a leitura, que permitirá, de alguma forma, dar sentido a outros/estranhos a esse contexto, quer com questionamentos, espanto, ou por tomar conhecimento do acontecido e nele buscar inspiração.

A leitura do conjunto tem uma conotação quantitativa na medida em que o software Picasa possibilitou reunir numericamente cada categoria, sob as quais foram indexadas as imagens. O leitor menos avisado lerá, à primeira vista, o número e, talvez, queira somar para efeito de totalização. Alerta-se, porém, que o dado numérico é subjetivo, pois uma fotografia poderá apresentar diferentes categorias em razão da polifonia do tipo fotográfico, da mesma maneira que a obra literária, parafraseando Humberto Eco, a obra literária tem como característica se parecer com um queijo suíço, com muitos furos, que serão completados pelo leitor a partir da(s) experiência(s). Assim é entendida a fotografia aqui organizada e lida (ECO, 1979 apud AGUIAR, 2003).

As categorias surgiram, ou melhor, elas se estamparam ao (re)ver, olhar, esquecer, retomar a observação e refletir sobre elas. Dessa forma, foi possível elaborar as seguintes categorias com indicadores de quantidade: Ação Cultural (2.544); Formação Continuada (228); Visita Programada (218); Biblioteca Monumento (527); Fazeres na Biblioteca (77); Acervo (29); Mobiliário (37); Equipamento (17); e Manutenção da Biblioteca (11). Segue uma ementa, a seguir, que descreve cada categoria eleita a título de esclarecimento e melhor compreensão da leitura interpretativa desse conjunto fotográfico.

A categoria ação cultural apresenta e representa diversos modos culturais da biblioteca, traduzidos em exposições, contação de histórias ou hora do conto, lançamento de livros, encontro com poetas, autores e leitores, confraternização no sentido amplo; mas concentra a atenção, sobremaneira, no público escolar e no público infantil. As exposições que integram esta categoria têm âmbito nacional, regional, nacional e internacional. Destaca-se, ainda, uma representação de momentos de confraternização, ambientes cuidadosamente arranjados que, de modo especial, fornecem imagens exuberantes de que a biblioteca, além de um lugar austero, sério e erudito, era e é, também, um lugar de comer, rir e compartilhar.

A categoria formação continuada é marca já das fotos sobre o impresso dos anos 80 e 90 do século XX. A formação continuada consiste em cursos de atualização profissional de curta duração oferecida aos funcionários ou, em outros momentos cursos, oficinas de interesse dos utilizadores/usuários da biblioteca. Pode-se dizer que essa categoria tem um caráter de permanência da biblioteca, isto é, as diferentes gestões dessa instituição que vêm, ao longo do tempo, promovendo e manifestando a preocupação com a qualificação no sentido mais amplo do papel que toda e qualquer Biblioteca Pública deve ter como preconizado no Manifesto da Unesco. 
A biblioteca-monumento, uma paisagem cultural -, guardiã da memória cultural e mesmo científica de Santa Catarina, emerge em meio aos edifícios da capital. Diferentes ruas Ihe dão acesso, como diferentes são os modos de se usufruir da instituição: leitura, estudo, lazer e informação. As imagens internas, do mesmo modo, apontam nessa direção, isto é, os diferentes espaços dialogam entre si a fim de cumprir sua função de biblioteca do estado de Santa Catarina.

Como as imagens externas convidam o leitor a entrar na biblioteca, aos poucos, outras imagens internas, retratadas na categoria bibliotecamonumento, guiam o olhar até o terceiro andar, focando o lugar dos fazeres técnicos, o acervo de pesquisa, funcionários, pesquisadores e, ainda, o lugar da administração e da gestão da instituição. Nesse conjunto de fotos, registra-se o chegar à biblioteca, o se anunciar e ser anunciado, o controle do ir e vir. Mas, aqui, o olhar também se dirige ao subsolo. As imagens são do vazio, do silêncio; porém, o vazio e o silêncio dialogam com as imagens da ação cultural, da alegria, do riso, do colorido, enfim, da confraternização que a instituição proporciona àqueles que vêm por diferentes razões à BPSC.

Dessas imagens, outras representações podem ser levantadas. $O$ primeiro andar, o salão de leitura - conversas, leitura, escrita - e mesmo olhares distantes, para pensar. $O$ espaço de trabalho dos funcionários, a singularidade constituída por estes para seu espaço de trabalho, quer sejam fotografias de familiares, quer sejam gravuras religiosas.

Os fazeres da biblioteca estão estampados no conjunto fotográfico tanto de seu fazer mais permanente (trabalhos técnicos) quanto o serviço de referência, esse último matizado por diferentes utilizadores, leitores ou consultes ao longo do tempo. Lembrando que o acervo, nesse fazer, é item inerente; afinal, a biblioteca é lugar do conhecimento em diferentes formatos.

A categoria mobiliário traduz a preocupação com o leitor da mais tenra idade, mas, também, mostra as diferentes aquisições desse objeto da biblioteca, pensando no conforto do leitor.

Uma representação dos aspectos tecnológicos e suas mudanças constantes se estampam na categoria equipamento. Nesses objetos, pode-se compreender que não só as tecnologias sofrem alterações, mas, junto com elas, as práticas bibliotecárias e as práticas de uso da biblioteca.

\section{Considerações de uma produção de sentidos}

Pela função de identificar, organizar, ler e reler o conjunto fotográfico dos itens impressos e digitais que nos propusemos como tarefa de pesquisa, arriscamo-nos a escrever algumas considerações a partir do sentido que essas fotografias produziram em nós, nesse trabalho investigativo.

$\mathrm{Na}$ esteira de Mauad (2008), entre o sujeito que olha e a imagem que elabora, há muito mais do que os olhos podem ver. A fotografia é 
uma elaboração do vivido, o resultado de um ato de investimento de sentido ou, ainda, uma leitura do real realizada mediante o recurso a uma série de regras que envolvem, inclusive, o controle de um determinado saber de ordem técnica.

Observa, ainda, a referida autora, que a fotografia é interpretada como resultado de um trabalho social de produção de sentido, pautado sobre códigos culturalmente convencionados. Pode-se dizer que se trata de uma mensagem que se processa através do tempo, constituído de unidades culturais, mas que, também, assumem aspectos sígnicos diferenciados, de acordo tanto com o contexto no qual a mensagem é veiculada, quanto com o local que ocupam no interior da própria mensagem (MAUAD, 1990 apud MAUAD, 2008).

A pergunta de pesquisa que norteou a leitura dessas fotografias foi: Quais as possíveis representações da e sobre a biblioteca como uma instituição pública de leitura? Assumimos algumas respostas frente à leitura dessas imagens. Isto é, que as mesmas revelam uma biblioteca pública voltada à ação cultural, uma instituição preocupada com a formação continuada, quer de seus funcionários, quer de interessados da comunidade local. As imagens revelam um edifício-monumento do conhecimento em meio a estabelecimentos financeiros e comerciais da capital catarinense; a permanência ou continuidade dos fazeres inerentes aos de uma biblioteca, isto é, serviços e tratamento de informação de práticas bibliotecárias que dão andamento ao seu cotidiano. As imagens também mostram um conjunto de mobiliário e equipamentos que apontam as diferentes fases tecnológicas da BPSC.

Podemos sintetizar dessa leitura que o conjunto fotográfico expõe, como noção de representação, uma instituição de leitura que se movimenta em favor do público infantil, um lugar de formação/educação e lazer para o adulto, um espaço sempre disponível, aberto a seus consulentes, leitores ou utilizadores. Por fim, dizer que as imagens capturadas em diferentes tempos assume uma produção de sentidos gerados do "clicar desse conjunto fotográfico", o qual resulta em um conjunto fotográfico como uma memória para se (re)conhecer a Biblioteca Pública de Santa Catarina (PBSC).

\section{Referências}

ACHUTTI, L. E. R. Fotoetnografia da biblioteca jardim. Porto Alegre: Editora UFRGS, 2004.

AGUIAR, A. A. et al. A escolarização da leitura. Belo Horizonte: Autêntica, 2003.

BARROS, A. et al. A grafia da luz na narrativa etnográfica. In: ACHUTTI, L. E. (Org.). Ensaios sobre o fotográfico. Porto Alegre: Unidade Editorial Porto Alegre, 1998. p. 100-108.

ECO, U. Leitura do texto literário: lector in fabula. Lisboa: Presença, 1979 apud AGUIAR, A. A. et al. A escolarização da leitura. Belo Horizonte: Autêntica, 2003 
KOSSOY, B. Fotografia \& história. 3. ed. São Paulo: Atêlie, 2009.

KOURY, M. G. P. Relações Imaginárias. In: ACHUTTI, L. E. R. (Org.). Ensaios sobre o fotográfico. Porto Alegre: Unidade Editorial Porto Alegre, 1998. p. 72-78.

MAUAD, A. M. Poses e flagrantes ensaios sobre história e fotografias. Niterói: EdUFF, 2008.

MAUAD, A. M. Sob o signo da imagem: a produção da fotografia e o controle dos códigos de representação social da classe dominante, no Rio de Janeiro, na primeira metade do século XX. Tese (Doutorado em História) - Programa de Pós-Graduação em História ICHF, GEG, Universidade Federal Fluminense, Niterói, 1990. Apud MAUAD, A. M. Poses e flagrantes ensaios sobre história e fotografias. Niterói: EdUFF, 2008.

PESAVENTO, S. J. História \& história cultural. 2. ed. Belo Horizonte: Autêntica, 2003.

PESANVENTO, S. J.; SANTOS, N. M.; ROSSINI, M. S. (Org.). Narrativas, imagens e práticas sociais: percursos em história cultural. Porto Alegre: Asterisco, 2008.

SANTOS, J. S. dos. Indexação de imagens fotográficas do acervo do laboratório de fotografia do Centro de Artes da Universidade do Estado de Santa Catarina. 2010. 40f. Trabalho de Conclusão de Curso (Graduação em biblioteconomia) - Universidade do Estado de Santa Catarina, Centro de Ciências Humanas e da Educação, Departamento de Biblioteconomia e Gestão da Informação, Florianópolis, 2010.

UNIVERSIDADE DO ESTADO DE SANTA CATARINA (UDESC). Programa Biblioteca Pública de Santa Catarina: um modelo de gestão. Florianópolis: Departamento de Biblioteconomia e Gestão da Informação, 2010. Relatório final (2008 - 2010).

VESTAL, D. A Integridade da Fotografia. In: ACHUTTI, L. E. R. (Org.). Ensaios sobre o fotográfico. Porto Alegre: Unidade Editorial Porto Alegre, 1998. p. 79-81. 